\title{
Pola Asuh Orang Tua Mempengaruhi Kemampuan Self Care Pada Anak Autisme
}

\author{
I Gusti Ayu Putu Satya Laksmi ${ }^{1 *}$, Ni Made Purnamaningsih ${ }^{2}$, Ni Luh Putu Devhy ${ }^{3}$ \\ ${ }^{1,2}$ Program Studi Sarjana Keperawatan, Sekolah Tinggi Ilmu Kesehatan Wira Medika Bali, ${ }^{3}$ Program \\ Studi Rekam Medis Informasi Kesehatan, Sekolah Tinggi Ilmu Kesehatan Wira Medika Bali \\ *Email: ayuputusatya@yahoo.com
}

\begin{abstract}
Background: Autism is one of the serious development disorders of a child, which causes problem in the ability of daily life, one of which is self care. The role of parents, especially of parenting parents is very influential for self care ability in autistic children.Aims of this study is to analize corelation betwen parenting parents to self care ability in autism. Methods: The study design uses Descriptive Correlation, that is a correlation between two variables is parenting and ability self care in autistic children. With a Cross-Sectional approach. The amount of samples used was 47respondents, using the Purposive sampling technique and collecting data using The Pediatric Evaluation of Disability Inventory with the test results using the contingency coefficient. That tested whether there is a correlation between two variables is parenting and ability self care in autistic children. Results: The results of study found the majority of parents implementing democratic parenting as many as 25 people (53,2\%) and 24 children $(51,1 \%)$ with the ability to self care quite capable. The test results using the contingency coefficient obtained of $p$ value of $0,000(p<0,05)$ which means that these results indicate a correlation of parenting with ability self care in autistic children, a correlation strength value of 0,659 (strong power). Conclusion: The researcher suggests that parents provide many positive activities in terms of eating and drinking, dreesing, personal hygiene, and toileting so that children can independently do self care.
\end{abstract}

Keywords : ability self care, autistic child, parenting

\section{PENDAHULUAN}

Anak merupakan individu yang masih bergantung pada orang lain dan lingkungan yang mampu memfasilitasi kebutuhan dasar serta untuk belajar mandiri, lingkungan yang dimaksud adalah orang tua atau keluarga dari anak. Setiap orang tua akan mengharapkan anaknya tumbuh dan berkembang secara sehat sesuai dengan tahap dan tugas tumbuh kembangnya (Susumaningrum, 2018). Kenyataan ada beberapa diantaranya memiliki anak yang mengalami autisme (YPAC, 2013). Anak autisme mengalami beberapa gangguan, dengan tiga gangguan utama yaitu mengalami gangguan interaksi sosial, gangguan komunikasi, dan gangguan perilaku (Wiyani, 2014).

Angka kejadian anak yang teridentifikasi autisme pada tahun $2017 \mathrm{di}$ Amerika Serikat yaitu sekitar 1 dari 68 anak atau 1,5\% dari anak usia 8 tahun (Centers for Disease Control and Prevention). Autisme lebih banyak terjadi pada anak laki-laki dibandingkan anak perempuan yaitu 4:1 dan terjadi pada 1520 dari 10.000 anak-anak (Nixon \& Mariyanti, 2018). Data dari Kementrian Pendidikan dan Kebudayaan jumlah anak autisme di Indonesia pada tahun 2017 mencapai 10.785 anak di Sekolah Luar Biasa (SLB). Jumlah anak autisme di Provinsi Bali mengalami peningkatan rata-rata $5,8 \%$ setiap tahunnya. Data dari Dinas Pendidikan Provinsi Bali tahun 2018/2019 jumlah anak autisme yang sudah bersekolah di Sekolah Luar Biasa (SLB) yaitu 154 orang, dimana kota Denpasar menempati urutan pertama dengan jumlah 125 anak. Angka kejadian di Pusat Layanan Autis Kota Denpasar pada bulan Januari 2020 terdapat 53 anak 
yang mengalami autisme (laki-laki berjumlah 46 anak dan perempuan berjumlah 7 anak). Angka cukup memprihatinkan, karena meningkatnya jumlah anak autisme dapat mempengaruhi sumber daya manusia yang berkualitas (Aristiani, 2019). Gangguan yang dimiliki anak autisme tersebut dapat menimbulkan berbagai dampak dalam kehidupannya seperti masalah kesulitan dalam kehidupan sehari-hari yaitu kurangnya kemampuan dalam melakukan kegiatan sehari-hari seperti kemampuan perawatan diri (self care) (Dewi \& Ainin, 2017). Hal ini didukung oleh penelitian Silfia (2018), bahwa anak autisme memiliki kemandirian yang terbatas, khususnya pada kemampuan untuk melakukan kebersihan diri. Hal ini sejalan dengan penelitian yang dilakukan oleh Solihah (2016), bahwa anak autis masih perlu dibantu terutama dalam mengguyur air dan memakai handuk setelah mandi.

Kemampuan self care pada anak autisme dapat ditingkatkan melalui beberapa upaya yaitu melalui pemberian terapi-terapi yang khusus diberikan pada anak autisme seperti terapi perilaku, terapi okupasi dan terapi fisik (Meranti, 2013). Selain itu, informasi dan pengetahuan juga penting dimiliki oleh orang tua atau pengasuh anak agar anak dapat menerapkannya di rumah dan orang tua dapat memberikannya melalui pola pengasuhan terhadap anaknya (Soetjiningsih \& Ranuh, 2013). Pola asuh orang tua dapat diartikan sebagai sikap dimana orang tua dapat membina dan mendidik anak-anaknya pada kehidupan sehari-hari. Dimana efektivitasnya dapat dilihat dari bagaimana cara anak berperilaku dalam kehidupan sehariharinya (Petranto, 2012). Perawat, khususnya perawat anak, mempunyai peran dalam pengkajian awal dan identifikasi perilaku anak yang mengarah pada autis, terutama pada masa bayi. Keterlambatan dalam diagnosa membuat hilangnya kesempatan untuk memberikan intervensi pada orangtua dan stimulasi perkembangan yang dapat memaksimalkan kesejahteraan anak (Phetrasuwan, 2009). Orangtua memerlukan bantuan dalam memahami perilaku anak mereka, mencari sumbersumber pendukung yang tepat, serta intervensi yang dapat memaksimalkan kemampuan anak (Phetrasuwan, 2009). Tujuan penelitian untuk mengetahui hubungan pola asuh orang tua dengan kemampuan self care pada anak autisme di pusat layanan autis kota Denpasar.

\section{METODE PENELITIAN}

Penelitian ini merupakan penelitian kuantitatif dengan desain deskripsi korelasional dan pendekatan cross sectional. Penelitian ini dilakukan di Pusat Layanan Autis Kota Denpasar pada tanggal 9 sampai 12 Maret 2020.

Populasi yang digunakan dalam penelitian ini yaitu orang tua dari anak autisme di Pusat Layanan Autis Kota Denpasar sebanyak 53 orang dengan teknik sampling yaitu purposive sampling sehingga mendapatkan sampel sebanyak 47 responden. Kriteria inklusi dalam penelitian ini adalah orang tua dari anak autisme yang bersedia menjadi responden dan orang tua yang tinggal serumah dengan anak autisme. Sedangkan kriteria eksklusinya adalah orang tua dari anak autisme di Pusat Layanan Autis Kota Denpasar tahun 2020 yang tidak hadir atau sekolah saat penelitian, orang tua yang memiliki anak autisme yang didiagnosa double (misalnya; autisme dan down syndrome, autisme dan ADHD, 
orang tua yang tidak mengasuh anak autisme misalnya yang mengasuhnya yaitu neneknya, bibinya atau saudara lainnya.

Pengumpulan data yang peneliti gunakan yaitu kuesioner pola asuh orang tua dan kuesioner kemampuan self care pada anak autisme yaitu PEDI (The Pediatric Evaluation of Disability Inventory) dengan menggunakan teknik analisis uji statistik non parametris yaitu Uji Koefisien Kontingensi. Kuesioner pola asuh orang tua sebanyak 20 item pertanyaan. Adapun 20 item pertanyaan diantaranya 5 item pola asuh demokratis pada poin, 5 item pertanyaan pola asuh, 5 item pola asuh permisif, 5 item pertanyaan pola asuh penelantar. Kuesioner pola asuh orang tua dan PEDI sudah dilakukan uji valid dan reliabilitas. Dikatakan pola asuh demokratis, jika skor pola asuh demokratis lebih besar dari skor pola asuh otoriter, pola asuh permisif, dan pola asuh penelantar. Dikatakan pola asuh otoriter jika pola asuh otoriter lebih besar dari skor pola asuh demokratis, pola asuh permisif, dan pola asuh penelantar. Dikatakan pola asuh permisif, jika skor pola asuh permisif lebih besar dari skor pola asuh demokratis, pola asuh otoriter, dan pola asuh penelantar. Dikatakan pola asuh penelantar, jika skor pola asuh penelantar lebih besar dari skor pola asuh demokratis, pola asuh otoriter, dan pola asuh permisif. Sedangkan kuesioner PEDI merupakan instrumen yang digunakan untuk mengukur kemampuan perawatan diri (self care) pada autisme. Instrumen modifikasi PEDI mencangkup kegiatan perawatan diri pada anak dengan disabilitas meliputi 32 item perawatan diri. Hasil pengukuran menggunakan total nilai skor 32-96, kemudian kemampuan perawatan diri dikategorikan berdasarkan cut off point menjadi kurang mampu skor 32-54, cukup mampu skor 55-75 dan mampu skor 76-96.

\section{HASIL PENELITIAN}

Tabel 1. Karakteristik Orang Tua Berdasarkan Usia, Pendidikan, Pekerjaan

\begin{tabular}{rcc}
\hline Karakteristik & Frekuensi (n) & Persentase (\%) \\
\hline Usia & & \\
a. Remaja akhir (17-25 tahun) & 4 & 8,5 \\
b. Dewasa awal (26-35 tahun) & 22 & 46,9 \\
c. Dewasa akhir (36-45 tahun) & 16 & 34 \\
d. Lansia awal (46-55 tahun) & 5 & 10,6 \\
\hline Pendidikan & & \\
a. SD & 4 & 8,5 \\
b. SMP & 6 & 12,7 \\
c. SMA & 24 & 51,1 \\
d. Perguruan tinggi & 13 & 27,7 \\
\hline Pekerjaan & & \\
a. Swasta & 5 & 10,6 \\
b. PNS & 4 & 8,5 \\
c. Wiraswasta & 7 & 14,9 \\
d. Ibu rumah tangga (IRT) & 31 & 66 \\
\hline Total & $\mathbf{4 7}$ & $\mathbf{1 0 0}$ \\
\hline
\end{tabular}


Berdasarkan tabel 1. didapatkan data yaitu mayoritas usia orang tua sebanyak 22 orang $(46,9 \%)$ adalah dewasa awal dengan pendidikan mayoritas sebanyak 24 orang $(51,1 \%)$ adalah SMA dan pekerjaan yang mayoritas s ebanyak 31 orang $(66 \%)$ adalah IRT.

Tabel 2. Karakteristik Anak Autisme Berdasarkan Usia, Jenis Kelamin

\begin{tabular}{lcc}
\hline Karakteristik & Frekuensi (n) & Persentase (\%) \\
\hline Usia & & \\
a. Anak-anak (5-11 tahun) & 21 & 44,7 \\
b. Remaja awal (12-15 tahun) & 23 & 48,9 \\
$\begin{array}{l}\text { c. Remaja pertengahan (15-18 } \\
\quad \text { ahun) }\end{array}$ & 3 & 6,4 \\
Jenis kelamin & 40 & 85,1 \\
a. Laki-laki & 7 & 14,9 \\
b. Perempuan & \multicolumn{1}{c}{$\mathbf{4 7}$} & $\mathbf{1 0 0}$ \\
\hline Total & & \\
\hline$\quad$ Berdasarkan tabel 2.didapatkan data & tahun) dengan jenis kelamin mayoritas \\
yaitu mayoritas usia anak sebanyak 23 & sebanyak 40 orang (85,1\%) adalah laki- \\
orang (48,9\%) adalah remaja awal (12-15 & laki.
\end{tabular}

Tabel 3. Distribusi Frekuensi Pola Asuh Orang Tua

\begin{tabular}{|c|c|c|}
\hline Pola Asuh Orang Tua & Frekuensi (n) & Persentase $(\%)$ \\
\hline Otoriter & 2 & 4,3 \\
\hline Demokratis & 25 & 53,2 \\
\hline Permisif & 20 & 42,6 \\
\hline Total & 47 & 100 \\
\hline
\end{tabular}

Tabel 4. Distribusi Frekuensi Kemampuan Self Care Pada Anak Autisme di Pusat Layanan Autis Kota Denpasar

\begin{tabular}{|c|c|c|}
\hline Kemampuan self care & Frekuensi (n) & Persentase $(\%)$ \\
\hline Mampu & 1 & 2,1 \\
\hline Cukup mampu & 24 & 51,1 \\
\hline Kurang mampu & 22 & 46,8 \\
\hline Total & 47 & 100 \\
\hline
\end{tabular}


Tabel 5. Hasil Analisis Hubungan Pola Asuh Orang Tua dengan Kemampuan Self Care Pada Anak Autisme di Pusat Layanan Autis Kota Denpasar

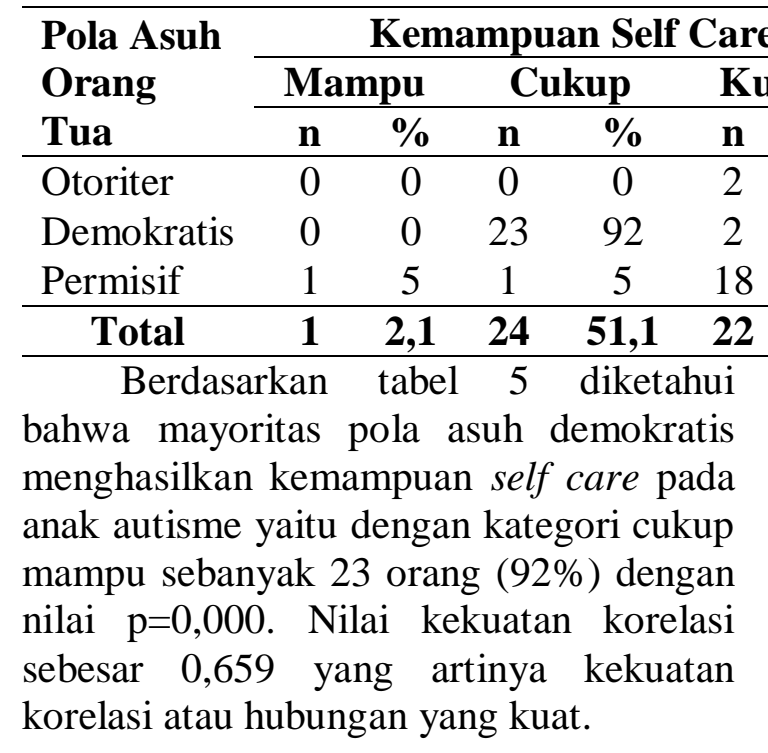

\section{PEMBAHASAN}

Berdasarkan hasil penelitian dapat dilihat bahwa ada hubungan pola asuh orang tua dengan kemampuan self care pada anak autisme.Kuat lemahnya korelasi dilihat dari nilai correlation coefficient. Hasil correlation coefficient pada penelitian ini menunjukkan korelasi yang kuat antara pola asuh orang tua dengan kemampuan self care pada anak autisme. Nilai koefisien korelasi bertanda positif ini menunjukkan bahwa semakin baik pola asuh yang diterapkan orang tua maka semakin baik kemampuan self care pada anak autisme. Pola asuh orang tua tersebut dipandang sebagai faktor penentu (determination factor) yang dapat mempengaruhi perkembangan kemandirian personal hygiene seperti mandi dan merawat diri.

Orang tua akan membimbing anaknya, sehingga mempengaruhi perkembangan anak menjadi lebih baik dan terarah, maka peran orang tua sangat penting. Teori Wong (2008) didukung oleh Tarwoto \& Wartonah (2015),

\begin{tabular}{|c|c|c|c|c|}
\hline \multirow{2}{*}{$\frac{\frac{\mathrm{e}}{\text { urang }}}{\%}$} & \multicolumn{2}{|c|}{ Total } & \multirow[t]{2}{*}{$\begin{array}{c}\mathbf{P} \\
\text { Value }\end{array}$} & $\begin{array}{l}\text { Correlation } \\
\text { Coefficient } \\
\end{array}$ \\
\hline & n & $\%$ & & \\
\hline 100 & 2 & 100 & & \\
\hline 8 & 25 & 100 & 0,000 & 0,659 \\
\hline 90 & 20 & 100 & & \\
\hline 46,8 & 47 & 100 & & \\
\hline
\end{tabular}

menyatakan bahwa orang tua sangat berperan penting dalam melatih dan mendidik dalam proses perkembangan anak autisme. Menurut Effendi (2012), orang tua yang mempunyai pengaruh yang besar bagi perkembangan anak autisme. Menjadi mandiri tersebut bukanlah hal yang dapat diperoleh dengan mudah, tetapi harus melalui proses yang harus dimulai dan dibina sejak usia dini. Kunci untuk menjadikan anak menjadi indivdu yang mandiri dan mampu sebenarnya dipengaruhi oleh berbagai hal dan salah satunya yaitu pola asuh orang tua.

Hasil penelitian ini didukung dari hasil penelitian yang dilakukan oleh Lestari \& Sopingi (2018), yang meneliti terkait Hubungan Pola Asuh Orang Tua dan Kemandirian Anak Autis di SLB Autisdimana hasil penelitian menunjukkan bahwa ada hubungan yang positif antara pola asuh orang tua dan kemandirian pada anak autis. Penelitian Hasrati (2016), yang meneliti terkait Hubungan Pola Asuh Orang Tua Terhadap Kemandirian Anak Autis Di SLB Autis Padang menunjukkan bahwa ada hubungan yang positif antara pola asuh orang tua terhadap kemandirian anak autis.

Peneliti berpendapat bahwa ketika orang tua memberikan pola asuh yang tepat kepada anaknya maka akan memberikan pengaruh yang besar terhadap perkembangan anak. Pola asuh 
yang tepat ditandai dengan adanya sikap orang tua memberikan tanggung jawab pada anak untuk mengatur sendiri kegiatan perawatan dirinya seperti mandi, mengganti baju, makan dan toileting, melibatkan anak dalam mengambil keputusan yang berhubungan dengan kemandirian anak dalam melakukan perawatan diri, menegur anak ketika anak tidak mau melakukan perawatan diri, memberikan pujian atau penghargaan pada anak apabila mampu melakukan perawatan diri, dan tidak melarang anak untuk melakukan perawatan diri. Hasilnya pola asuh ini dapat mendorong anak untuk dapat menjadi mampu dan mandiri.Pada penelitian ini, terdapat beberapa keterbatasan pada penelitian ini yaitu tidak adanya observasi langsung kepada responden tentang pola asuh yang diberikan kepada anak dan kemampuan self care pada anak autisme, sehingga peneliti tidak mengetahui banyak bagaimana pola asuh yang diberikan pada anak autisme sehingga mampu melakukan self care. Selain itu, peneliti belum dapat mengendalikan faktor pemicu, yang menyebutkan bahwa faktor yang mempengaruhi kemampuan self care pada anak autisme ada faktor internal (faktor emosi dan faktor intelektual) dan faktor eksternal (lingkungan, karakteristik sosial, stimulus, cinta dan kasih sayang, dan kualitas informasi).

\section{KESIMPULAN DAN SARAN}

Terdapat hubungan yang signifikan antara pola asuh orang tua dengan kemampuan self care pada anak autisme di Pusat Layanan Autis Kota Denpasar dengan nilai kekuatan korelasi 0,659 (kekuatan kuat) antara variabel. Semakin baik pola asuh yang diterapkan orang tua maka semakin baik kemampuan self care pada anak autisme di Pusat Layanan Autis Kota Denpasar.

Guru di Pusat Layanan Autis Kota Denpasar agar lebih meningkatkan lagi dalam memberikan contoh, perhatian dan perilaku dalam self care pada siswa dan dapat memberikan edukasi dan informasi dengan merencanakan dan mengadakan penyuluhan atau pelatihan khusus bagi orang tua anak autism. Kepada Orang tua diharapkan agar lebih meningkatkan pengetahuan yang terkait dengan kondisi dan kebutuhan anak autisme dengan mengikuti pelatihan atau penyuluhan yang diadakan di Pusat Layanan Autis Kota Denpasar serta memberikan banyak kegiatan positif bagi anak autisme dalam melatih hal self care.

\section{DAFTAR RUJUKAN}

Aristiani, K. W. (2019). Hubungan Pola Asuh Orang Tua Dengan Komunikasi Interpersonal Anak Autis. Skripsi: STIKes Wira Medika Bali.

Dewi \& Ainin. (2017). Peranan Pola Asuh Orang Tua Terhadap Kemandirian Personal Hygiene pada Anak Autis di SDN Percobaan Surabaya. Jurnal Pendidikam Khusus. Retrieved from https://jurnalmahasiswa.unesa.ac.id/i ndex.php/jurnalpendidikankhusus/ar ticle/view/18925/17279

Agustus 2019)

Effendi, M. (2012). Pengantar Psikopedagogik Anak Berkelainan. Jakarta: PT. Bumi Aksara.

Hasrati, M. (2016). Hubungan Pola Asuh Orang Tua Terhadap Kemandirian Anak Autis Di Slb Autis Padang. Retrieved from 
http://scholar.unand.ac.id/22078/ (7 Desember 2019)

Lestari \& Sopingi. (2018). Hubungan Pola Asuh Orang Tua dan Kemandirian Anak Autis. Retrieved from http://journal2.um.ac.id/index.php/jo /article/view/4404 (11 Januari 2020)

Meranti, T. (2013). Psikolog Anak Autis (Pertama). Yogyakarta: Familia.

Nixon \& Mariyanti, S. (2018). Gambaran Kemandirian Anak Penyandang Autisme yang Mengikuti Program Aktivitas Kehidupan Sehari Hari (AKS). Jurnal Psikologi, 10(2), 91107. Retrieved from https://www.neliti.com/publications/ 127101/gambaran-kemandiriananak-penyandang-autisme-yangmengikuti-program-aktivitas Desember 2019)

$(28$

Petranto. (2012). Rasa Percaya Diri Adalah Pantulan Pola Asuh Orangtuanya.

Phetrasuwan, S., Miles, M.S., \& Mesibov, G. B. (2009). Defining autism spectrum disorders. Journal for Specialist in Pediatric Nursing, 14, 3, 206-209.

Silfia, M. (2018). Hubungan Pola Asuh Orangtua Terhadap Kemandirian Kebersihan Diri (Personal Hygiene) Anak Autis Di Slb Harmoni Gedangan Sidoarjo. 1-16. Retrieved from https://jurnalmahasiswa.unesa.ac.id/i ndex.php/jurnal-pendidikankhusus/article/view/25546/23420
(22 Agustus 2019)\%0A\%0A

Soetjiningsih \& Ranuh. (2013). Tumbuh Kembang Anak. Jakarta: EGC.

Solihah, U. (2016). Pembelajaran Bina Diri Mandi Pada Anak Autis Di Slb Autisma Dian Amanah Yogyakarta. (April). Retrieved from http://journal.student.uny.ac.id/ojs/o js/index.php/plb/article/viewFile/16 61/1443 (7 Desember 2019)

Susumaningrum, L. A. P. P. J. V. S. R. (2018). Hubungan Parenting Self Efficacy Dengan Kemampuan Melakukan Activity Daily Living (ADL) Pada Anak Autis Di SLB-B \& Autis TPA Jember. https://doi.org/10.1017/CBO978110 7415324.004

Tarwoto \& Wartonah. (2015). Kebutuhan Dasar Manusia dan Proses Keperawatan. Jakarta: Salemba Medika.

Wiyani. (2014). Buku Ajar Penanganan Anak Usia Dini Berkebutuhan Khusus (pertama). jakarta: ARRUZZ MEDIA.

YPAC. (2013). Buku Penanganan dan Pendidikan Autis di YPAC. Retrieved from http://ypacnasional.org/bukupenanganan-dan-pendidikan-autisdi-ypac/. (22 Agustus 2019) 